\title{
BERGERS, VÉGÉTARIENS ET CLOCHARDS. SOUS-CULTURES ET CONDUITES MARGINALES ALIMENTAIRES DANS LE SUD-OUEST DE LA FRANCE (XVII ${ }^{\mathrm{E}}-\mathrm{XXI^{ \textrm {E } }}$ SIECLES)
}

\author{
Shepherds, Vegetarians and Tramps: Food Subcultures and \\ Marginal Ways of Eating in Soutbwest France (17th-21 $21^{\text {st }}$ Centuries)
}

\author{
Frédéric DUHART ${ }^{1}$ \\ Université de Mondragon
}

\section{Resumen}

Después de una breve reflexión sobre las culturas alimentarias y su estudio, el texto se centra en el análisis de unas de las subculturas y conductas marginales alimentarias observables en el Sudoeste de Francia desde comienzos del siglo XVII hasta la actualidad. Se consideran primero las culturas alimentarias de los pastores trashumantes del Pirineo y de Aubrac; su característica más relevante era que la vida temporal lejos de los pueblos hacía que pequeñas comunidades masculinas tenían que cocinar a diario en la ausencia de las mujeres que lo hacían por lo regular en esta región. Después, el texto analiza la historia del vegetarianismo/veganismo en el Sudoeste de Francia. JeanAntoine Gleizès adoptó su modo de vida vegetariano y escribió su obra en esta region. Conducta marginal en sus inicios, el vegetarianismo se convirtió localmente en una auténtica contracultura. Terminaremos con el estudio de las conductas alimentarias de los más pobres, insistiendo sobre la situación de los indigentes sin hogar: son adaptaciones a contextos muy especiales en los cuales importa mucho ser «ingenioso». Palabras clave: alimentación, cocina, pastor, vegetarianismo, indigente, marginalidad

\section{Abstract}

After general comments on food cultures and their study, I consider some food subcultures and marginal ways of eating in Southwest France from the $17^{\text {th }}$ century

1 Enseignant-chercheur, Faculté des Sciences Gastronomiques de l'Université de Mondragon (Espagne). Courrier électronique : frederic.duhart@orange.fr. Fecha de recepción del artículo: 2 de noviembre de 2017. Fecha de aceptación: 21 de diciembre de 2017.

STVDIVM. Revista de Humanidades, 23 (2017) ISSN: 1137-8417, pp. 81-111 
to the present day. I first discuss the transhumant pastoralist food cultures in Pyrenees and Aubrac. Their main characteristic was that the temporary life away from the villages led small man communities to cook daily in the absence of women that normally did in this region. Then, I consider the history of the vegetarianism/ veganism in Southwest France. Jean-Antoine Gleïzès adopted his vegetarian lifestyle and wrote his books in this region. Marginal way of eating at its beginning, vegetarianism locally evolved into a real counter-culture. Lastly, I discuss the poor people marginal ways of eating, especially the homeless ones. They are adaptations to special contexts in which «being resourceful» is essential.

Key words: food, cooking, shepherd, vegetarianism, homeless, marginality

\section{INTRODUCTION}

Il est facile aujourd'hui, après des décennies d'observation ethnographique et l'abandon justifié de l'idée qu'il existait des races humaines, de décrire le comportement alimentaire d'Homo sapiens en quelques mots. L'acte de manger est, dans le cas de notre espèce, bioculturel — tout à la fois, sous une forme inextricable, éminemment biologique et éminemment culturel. Tout est dit. Mais, si nous en restions là, je me sentirais bien vite dans la position du lecteur qui résume Guerre et paix en disant que l'action se déroule en Russie. En effet, si l'humanité est une, ses façons d'être au monde en mangeant sont extrêmement diverses et le sont d'autant plus qu'elles ont changé au cours du temps.

Nous pouvons admettre d'emblée, pour esquiver un débat épistémologique classique, que chacune de ces réponses à la nécessité nutritionnelle est une culture alimentaire du moment qu'elle est produite par un groupe d'êtres humains. Si l'on souhaite étudier ces cultures alimentaires, il devient nécessaire de remarquer ce qui les différencie entre elles ou, pour le dire autrement, de définir le groupe humain associé à chacune d'entre elles. Ce faisant, il apparaît immédiatement que le véritable problème pour le chercheur est le choix d'une échelle d'observation. En effet, il s'exerce toujours un arbitraire plus ou moins assumé au moment de diviser l'humanité pour l'étudier. Claude Lévi-Strauss décrivit les bases de la diversité des cultures indigènes américaines (1987 [1952] : 17):

[...] ce gros fragment d'humanité détachée consistait en une multitude de sociétés, grandes et petites, qui avaient entre elles des contacts fort étroits. Et à côté des différences dues à l'isolement, il y a celles, tout aussi importantes, dues à la proximité : désir de s'opposer, de se distinguer, d'être soi. Beaucoup de coutumes sont nées, non de quelque nécessité interne ou accident favorable, 
mais de la seule volonté de ne pas demeurer en reste par rapport à un groupe voisin qui soumettait à un usage précis un domaine où l'on n'avait pas songé soi-même à édicter des règles.

Son propos peut être transposé à l'Europe occidentale. Nous pouvons identifier une quantité considérable de cultures alimentaires sur cette portion de l'œkoumène, parce que sa population est organisée en une multitude de sociétés, grandes et petites. Celles-ci sont d'autant plus nombreuses que "société » doit d'être entendue ici dans son sens de « communauté organisée d'individus ». Une famille est une société minuscule, l'ensemble des sujets d'un empire ou des citoyens d'une fédération d'états en forme une gigantesque. Des cultures alimentaires peuvent être identifiées à l'échelle de ces deux extrêmes, et logiquement à tous les niveaux intermédiaires entre elles. Au début des années 2000, par exemple, j'ai fait la connaissance d'un membre d'une famille rurale du piémont pyrénéen central dans laquelle le cochon d'Inde (Cavia porcellus) était consommé depuis au moins deux générations. Dans une région où l'écrasante majorité de la population ne le considérait pas, ce petit rongeur pouvait légitimement définir une culture alimentaire particulière. Pour leur part, des différends commerciaux avec les Etats Unis rappellent régulièrement un trait de la culture alimentaire commune à l'ensemble des citoyens de l'Union Européenne : ils ne sont pas et ne veulent pas devenir des consommateurs de « bœuf aux hormones ». ${ }^{2}$ Dans l'absolu, évidemment, l'observation des cultures alimentaires est pertinente à n'importe quelle échelle. C'est au chercheur de décider celle qui lui permet d'aborder avec le plus de finesse possible la problématique qui l'intéresse.

Evoquer des cultures alimentaires associées à des territoires conduit à prendre en compte le fait que des êtres humains peuvent se déplacer au cours de leur existence. Une culture alimentaire peut évidemment faire partie du bagage mental qu'un individu conservera toute sa vie, quand bien même il s'éloignera du territoire où il l'a acquise. Songeons aux recettes écrites par des déportées au camp de Terezín, victoire absolue sur un régime nazi qui tenta de nier leur humanité avant de les faire mourir de faim (De Silva, 1996). Néanmoins, la matérialisation d'une culture dans des actes culinaires ou alimentaires se déroule toujours dans un lieu. Logiquement, cela peut limiter l'expression concrète de la culture alimentaire des membres d'une communauté immigrée loin de sa terre d'origine, notamment par l'absence ou l'inaccessibilité de certains ingrédients. Un individu ne peut pas cuisiner

2 F. Aubret, "Le retour de la guerre du bœuf aux hormones ", La Tribune, 17/02/2017. 
ou manger ailleurs que là où il se trouve. Par conséquent, même s'il existe des cultures alimentaires qui ne sont pas associées à un territoire dans l'absolu, les membres d'un groupe associé à de telles cultures les vivent dans des espaces géographiques précis. Prenons pour exemple une culture alimentaire associée à une croyance religieuse. La Torah définie les traits fondamentaux de la culture alimentaire que doit être celle de l'ensemble du peuple juif, mais chaque communauté hébraïque est installée quelque part dans le monde. Cela conduit concrètement à l'existence de nombreuses façons de «manger à la juive » selon les lieux et au cours du temps (Toaff, 2000 ; Greeenspoon et alii, 2005).

Quelle que soit la taille du groupe qui lui est associé, une culture alimentaire se caractérise par des aspects qui la distinguent des autres. Ils peuvent être d'autant plus divers qu'ils n'ont parfois de l'importance que parce qu'un groupe a choisi de les mettre avant pour se distinguer de ses voisins. Dans le sud-ouest de la France, par exemple, il y existe des contrées dans lesquelles le foie gras de canard doit présenter la couleur que lui confère un gavage avec du maïs blanc; dans d'autres, elle doit être celle qui s'obtient avec du maïs jaune. Mais si deux groupes peuvent se différencier sur des détails, ils peuvent aussi se fédérer en acceptant d'oublier certaines divergences pour retenir des dénominateurs communs, des éléments fédérateurs. Cette capacité est essentielle, car c'est elle qui sous-tend l'existence de cultures alimentaires qui ne soient pas seulement propres à des groupes extrêmement réduits. En ce début de XXI ${ }^{e}$ siècle, les produits des palmipèdes gras fédèrent ainsi les cultures alimentaires d'un vasteSud-Ouestformé par les départements qui constituaient les anciennes régions Aquitaine et Midi-Pyrénées et des cantons situés sur leurs marges (Duhart, 2009 : 367-372).

Dans le reste de ce texte, notre attention se portera exclusivement sur cette région, plus précisément, sur ceux de ses habitants qui cuisinent et se nourrissent différemment. En effet, nous délaisserons les usages et les représentations alimentaires partagés par le plus grand nombre, pour considérer les façons d'être au monde en mangeant qui distinguent des minorités du reste de la société. Lorsqu'elles sont associées à un groupe, elles sont des sous-cultures alimentaires. Quand elles sont le fait d'individus isolés, il s'agit de conduites marginales alimentaires. Une multitude de sous-cultures et de conduites marginales alimentaires peuvent être rencontrées dans le sud-ouest de la France. Nous nous contenterons d'observer ici, en prenant en compte la longue durée : la sous-culture alimentaire des bergers transhumants, le végétarisme et les conduites marginales alimentaires des plus démunis. 


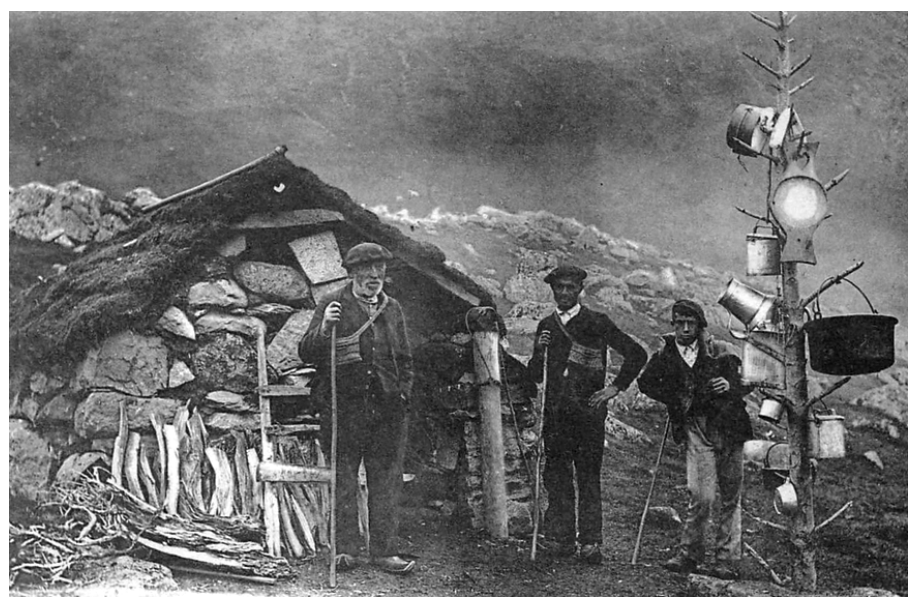

Figure 1 : Bergers dans les environs de Cauterets (Hautes-Pyrénées), déb. $\mathrm{XX}^{\mathrm{e}}$ siècle.

\section{Manger en Berger transhumant, CUISINER LOIN DES FEMMES}

Les systèmes pastoraux traditionnels de certaines vallées des Pyrénées et du plateau de l'Aubrac conduisirent des gardiens de troupeaux transhumants à se nourrir pendant plusieurs semaines à l'écart des villages [Figures 1 et 2]. Biensûr, les activités quotidiennes des pasteurs purentvarier considérablement selon la composition des cheptels placés sous leur vigilance et l'orientation locale de l'élevage. Tout aussi logiquement, leurs pratiques alimentaires purent sensiblement varier dans le détail selon les lieux et les époques. Toutefois, une grande majorité de bergers transhumants connurent une situation identique : ils durent cuisiner avec des ressources alimentaires limitées dans un isolement relatif, caractérisé d'une manière remarquable par l'absence de femmes. Dès au moins la fin du Moyen Age, en effet, des bergères ou des vachères n'accompagnèrent les troupeaux transhumants dans cette région que d'une façon exceptionnelle (Le Roy Ladurie, 1982 [1975] : 159-160 ; Garric, 2001 : 49-50).

Sur les estives pyrénéennes, les pasteurs combinaient les vivres qu'ils avaient amenés avec des denrées tirées des alentours de leur habitat temporaire. Lorsque leurs troupeaux étaient orientés vers la production de fromage ou de beurre, ils pouvaient utiliser abondamment des sous- 


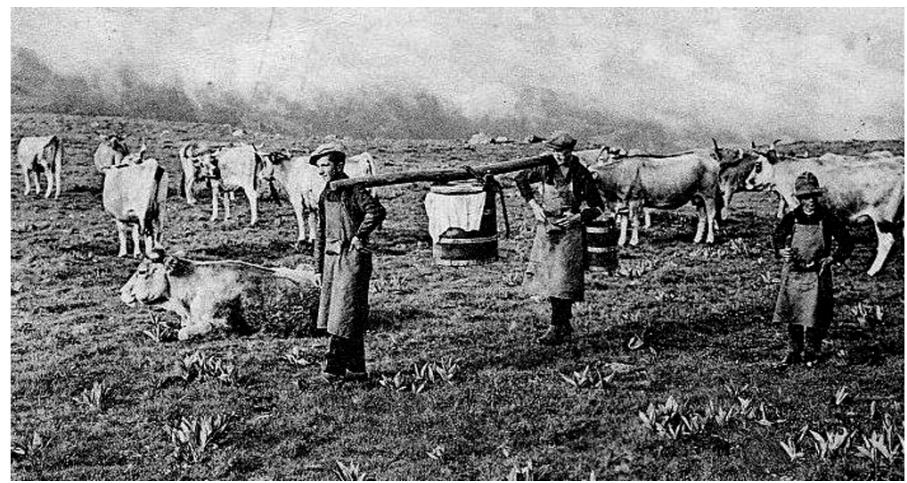

Figure 2 : Buronniers sur une estive de l'Aubrac (Aveyron), déb. XX ${ }^{\mathrm{e}}$ siècle.

produits de celle-ci. Dans les années 1670, par exemple, les bergers bigourdans rencontrés par Louis de Froidour se nourrissaient pour l'essentiel de petit-lait bouilli avec « quelques herbages » et d'une pâte « de blé, de millet, ou d'orge » cuite sous la cendre (1892: 44). Au début du XX siècle, le résidu de la fabrication fromagère continuait d'être employé dans certaines vallées pyrénéennes. Les bergers du Vicdessos en tiraient pour leur usage un aliment frais : le bourrassat (Taillefer, 1939: 214). Quant à ceux d'Irouléguy, ils consommaient parfois zenbera, un fromage obtenu en récupérant les particules de caillé en suspension dans le petit-lait (Etniker, 1990 : 219). Une telle permanence ne doit pas faire oublier qu'il y eut aussi des introductions notables dans le paysage alimentaire des accompagnateurs de troupeaux. Au début du XIX ${ }^{\mathrm{e}}$ siècle, par exemple, la pomme de terre était déjà devenue un complément essentiel des produits laitiers dans la ration quotidienne des pasteurs de certaines vallées ariégeoises (Dardenne, 1990 [1805] : 302). D’autres produits, en revanche, demeurèrent tardivement d'un usage assez limité. Le chocolat chaud et le café, par exemple, ne commencèrent à faire l'objet d'une consommation régulière dans la majorité des cabanes de bergers souletines qu'à une date avancée du XXe siècle (Peillen et Peillen, $1965: 59$ ). Au cours des dernières décennies dudit siècle, l'ouverture de routes de montagne put faciliter considérablement les relations entre les pâturages d'altitude et le bas de la vallée. Lorsqu'elle n'entraîna pas une modification totale du système pastoral local, elle permit un meilleur approvisionnement voire réapprovisionnement des bergers transhumants. Au début des années 2000, par exemple, de nombreux produits achetés en grande surface 
accompagnaient les conserves et les charcuteries " maison » dans les réserves des dernières cabanes en activité dans la vallée d'Aspe ${ }^{3}$.

Sur le plateau de l'Aubrac, la diète du cantalès et des autres travailleurs des burons ressembla fort à celle des pasteurs pyrénéens. Les laitages y tenaient une place considérable, en particulier un sous-produit de la production fromagère obtenu par le barattage de la crème extraite du petitlait : le burre de montana (Girou de Buzareingues, 1833 : 17). L'usage de cet aliment se maintint jusqu'à l'abandon des burons dans la seconde moitié du $\mathrm{XX}^{\mathrm{e}}$ siècle. Cependant, la composition des provisions fournies aux buronniers par leurs employeurs se diversifia sensiblement au cours du temps. Dès le $\mathrm{XIX}^{\mathrm{e}}$ siècle, par exemple, la pomme de terre et le lard y apparurent régulièrement aux côtés du pain (Marre, 1904 ; Merlin et Beaujour, 1978 : 123). En revanche, le café et le chocolat n'y firent qu'une apparition très tardive et limitée, seulement grâce à la générosité de quelques patrons (Garric, 2001 :210). La ration alimentaire pouvait être complétée par l'apport d'un petit jardin. A la fin des années 1960, celui du buron du Puech Cremat fournissait des choux des salades et des poireaux (Rivière, 1973 : 128-129).

Sur le plateau de l'Aubrac et dans les Pyrénées, quelques nourritures venaient exceptionnellement rompre la monotonie du quotidien alimentaire. Il y avait notamment les truites (Salmo trutta fario) capturées à la main ou les denrées qu'elles permettaient d'obtenir directement par un troc ou grâce à l'argent de leur vente (Garric, 2001 : 209). ${ }^{4}$

Lieux de vie et de travail à l'équipement sommaire, les cabanes des Pyrénées ou de l'Aubrac offraient globalement les mêmes conditions pour l'accomplissement des tâches culinaires. Là où il y en avait, les ustensiles nécessaires à la production fromagère voisinaient avec ceux qui servaient à la préparation des repas. Certes, l'usage ne les confondait pas. ${ }^{5}$ Mais leur rencontre situait les actions alimentaires des bergers dans un cadre très particulier. Nous pouvons voir sur les photographies d'intérieurs de cabanes basques prises par Jacques Blot dans les années 1980, par exemple, des cuillères et des casseroles pendues au dessus de bidons à lait et de formes à fromage (1984).

3 Voir notamment les photographies d'intérieurs de cabane dans Faustin, 2004 ; En particulier p. 19 (cabane de Cap de Guerren) et p. 110 (cabane de Salistre).

4 Arch. dép. Haute-Garonne, $\mathrm{Br} 4^{\circ} 110$ (Cirés).

5 Dans les burons de l'Aubrac, par exemple, le couteau avec lequel le pâtre coupait le caillé ne servait jamais à faire autre chose (Rivière, 1972: 64). 
Dans ces cabanes encombrées d'ustensiles et d'outils nécessaires à l'activité pastorale, la batterie de cuisine se réduisit généralement à peu de choses. Dans les hautes vallées béarnaises du début du XX siècle, elle se résumait à l'ordinaire à un pot, un gril, une poêle et quelques menus objets (Cazaurang, 1983 : 123). Après la seconde guerre mondiale, la bouteille de Butagaz raccordée à un réchaud commença à prendre une place dans les cabanes. Son apparition n'apporta pas de changements notables dans les manières de manger, mais elle marqua l'apparition d'un point de chaleur réservé à l'action culinaire, alors que le feu de la cheminée avait toujours été multifonctionnel. Le rythme des repas des bergers variait selon les besoins de leurs troupeaux. Les brebis et les vaches en production laitière imposaient des journées particulièrement éprouvantes. Dans ses mémoires, un berger de la vallée d'Aspe actif de 1912 à 1969 décrivit comment lui et son compagnon de cabane se nourrissaient pendant la phase de lactation de leurs brebis. Le déjeuner se plaçait après la traite du matin et la confection d'un fromage, tandis que le second repas de la journée se déroulait au retour du pacage et précédait la traite du soir suivie éventuellement de la confection d'un second fromage (Lamazou, 1988 : 122). Au milieu de l'été, lorsque les brebis cessaient de produire du lait, les bergers disposaient de plus de temps pour exercer d'autres activités, notamment prendre plus de temps pour cuisiner et manger (Duvert et alii, $1998: 254$ ).

Sur l'estive, l'homme devait cuisiner puisqu'il n'y avait pas de femme pour le faire. La cuisine des bergers se réduisait à quelques recettes, déterminées par le peu d'ustensiles et le stock d'ingrédients disponibles dans les cabanes. Leurs techniques de base étaient la cuisson à l'eau, au gril ou à la poêle ; elles pouvaient parfois se combiner entre elles. L'olia des bergers béarnais des années 1920, par exemple, était une soupe obtenue en faisant bouillir des bouts d'oignons, d'ail et de lard frit dans une eau qu'on jetait ensuite sur des morceaux de pain (Lefebvre, 1928 : 47). Une partie au moins de la cuisine quotidienne était réalisée en commun lorsque plusieurs bergers cohabitaient dans une même cabane. Dans les cujalas qu'Etienne Lamazou fréquenta en vallée d'Aspe, par exemple, il était d'usage de faire à tour de rôle la soupe pour l'ensemble de la cabane mais de "s'arranger chacun de son côté et à son gré » pour préparer l'accompagnement de celleci $(1988$ : 148). La cuisine des bergers, indéniablement masculine par les conditions de sa réalisation, n'était pas construite symboliquement à la différence de certaines pratiques culinaires typiquement associées au genre masculin autour d'une opposition avec la cuisine domestique des femmes. Sans doute, était-elle trop quotidienne pour cela. Le pasteur transhumant se débrouillait avec ce qu'il avait sous la main parce qu'il fallait bien 
s'alimenter en l'absence de cuisinière. Il ne préparait pas ostensiblement un mets pour s'affirmer en tant que mâle. Les descentes d'estive étaient d'ailleurs des occasions de retrouver avec un bonheur, qui n'était pas dissimulé, des nourritures ordinaires qui manquaient sur les hauteurs. Dans l'Aubrac des années 1930, il s'agissait notamment de l'omelette, de la soupe au fromage ou du vin (Garric, 2001 : 52). La cuisine des bergers transhumants était en quelque sorte une adaptation du savoir culinaire domestique à des conditions extrêmes. Non seulement des ustensiles et des ingrédients manquaient, mais l'homme devait aussi faire une cuisine de rôle féminin. Sur les estives exploitées par certaines communautés de Soule et de Basse-Navarre, la préparation des repas à l'intérieur de la cabane parachevait même le jeu de rôles qui instaurait une homologie entre le berger/fromager et la maittresse de maison/mère, la confection du fromage venant se poser ici en équivalent symbolique de conception d'un enfant. En ces lieux, en effet, une répartition journalière des tâches liées à l'entretien du troupeau mis en commun et à la confection des fromages s'opérait entre les différents bergers cohabitant dans la même cabane (Duvert et Aguergaray, 1993 : 143-146). Chacun remplissait conditionnement un rôle fixé par la tradition locale. Dans les années 1940, par exemple, un berger qui rejoignait une cabane de Saint-Just-Ibarre, par exemple, était successivement : neskatoa [la servante], artzain mutila [le pâtre], artzain nausi [le maître berger] et etxanderea [la maitresse de maison]. Les deux fonctions féminines étaient associées à la confection des fromages et aux tâches ménagères, cuisine y compris (Barandiarán, 1955 : 42-45). A SainteEngrâce, où le berger occupait tour à tour six rôles au début du XX $\mathrm{XX}^{\mathrm{e}}$ siècle, " la maîtresse de maison » prenait ses fonctions en fin d'après-midi : il confectionnait un premier fromage et préparait les galettes de maïs qui constituaient le repas du soir. Le lendemain matin, il allumait le feu, faisait son second fromage et préparait pour les six bergers les galettes de maïs servies au premier repas. Il confectionnait ensuite le repas du midi puis s'occupait de la vaisselle et de diverses tâches ménagères. "La servante » l'aidait dans ces différentes tâches. Dans les années 1970, le système de travail collectif traditionnel souletin était en crise. Cependant, la répartition des tâches entre «le berger » et la « maîtresse de maison » se maintint dans la plupart des syndicats. A Ligoleta, il n'y avait plus que deux bergers qui cohabitaient dans la cabane. Quand ils travaillaient à l'extérieur, l'un était «le berger » et l'autre «l'aide-berger». Une fois à l'intérieur, ils devenaient « la maîtresse de maison» et «la servante » (Ott, 1993 [1981] : 147-224).

Les formes de la transmission du savoir culinaire aux bergers débutants étaient variables. En 1914, les jeunes occupants de la cabane du col 
d'Arhansus apprirent l'art de préparer les galettes de maïs (pastetxak) d'un berger qui avait derrière lui une cinquantaine de montées à l'estive. Plus exactement, celui-ci leur enseigna l'art de préparer la pâte, de la pétrir, de la partager et de façonner les galettes. En effet, ils ignoraient tout de cette tâche de rôle féminin à laquelle ils n'avaient jamais prêté attention dans le cadre de la maison familiale parce qu'ils étaient des garçons. En revanche, les principes de sa cuisson leur rappelèrent rapidement des choses vues au moment des repas dans la cuisine où officiait leur mère (Duvert et alii, 1998 : 236). Lorsque, à l'âge de 11 ans, Erramun Etchebarne se préparait à monter garder du bétail à Iraty pour la première fois de sa vie, son père lui expliqua qu'afin d'apprendre à se faire à manger, il pouvait commencer par regarder comment sa mère préparait les galettes de maïs (1989 : 29).

En général, la cuisine des bergers demeura une cuisine de rôle féminin, quotidienne et peu valorisée socialement. A la faveur d'un intérêt pour les spécialités culinaires locales, cependant, quelques mets propres aux pasteurs purent voir leur statut changer. En terres d'Aubrac, par exemple, l'Aligot s'affirma comme un glorieux marqueur d'identité dès la fin du XIX siècle. Dès lors, il fut célébré comme un plat né dans la cuisine masculine des burons et la capacité des cantalès à le préparer fut louée (Affre, 1974 [1903] : 8). A la différence d'autres plats à base de pommes de terre que les buronniers consommaient très régulièrement, toutefois, l'aligot avait toujours été préparé de manière occasionnelle par les pasteurs, car sa préparation requérait du fromage frais, tomme, un produit qu'ils ne pouvaient se permettre de manger avec une grande régularité. D’une façon très classique, la cuisine démonstrative et exceptionnelle de rôle masculin éclipsait celle nourricière et quotidienne de rôle féminin.

Lorsque les bêtes descendaient des pâturages d'altitude, les bergers retournaient durant au moins une quinzaine de jours dans un cadre domestique au sein duquel seules les femmes cuisinaient (Lefebvre, 1928 : 57). En effet, si beaucoup d'entre eux se réinstallaient pleinement dans les rythmes de la vie familiale jusqu'au retour de la belle saison, les pasteurs de certaines vallées pyrénéennes partaient avec leurs troupeaux, à l'issue d'une brève période de transition, vers des hivernages plus ou moins lointains. Leurs conditions de vie variaient considérablement d'une terre d'accueil à l'autre. Jusque dans la première moitié du XIXe siècle, par exemple, les vachers béarnais qui descendirent dans les landes de Gascogne retrouvèrent une vie de cabane assez proche de celle qu'ils connaissaient en montagne (Soulet, 1974 : 116-117). Au début du XX siècle, les bergers d'Iraty qui hivernaient aux environs d'Hasparren logeaient dans des bordes situées à 
proximité de la ferme qui les accueillaient mais ils y vivaient en relative autonomie. Ils s'y nourrissaient essentiellement de laitages auxquels s'ajoutaient les vivres fournis hebdomadairement par le propriétaire du troupeau (Etniker, 2000 : 532). A la fin des années 1930, en revanche, les bergers qui hivernaient à Hélette étaient logés et nourris dans les maisons qui les recevaient moyennant un paiement en monnaie, en fromage, etc. (Barandiarán, 1987: 69). Dans les années 1890, le vacher général qui assurait la garde des bovins ossalois sur les terres basses du Pont-Long était logé et nourri par les propriétaires des biens limitrophes en contrepartie de la fumure apportée par les bêtes. Plutôt mangeur de pain de méteil, il devait alors s'accommoder de la méture de mais en usage dans cette zone du piémont (Capdevielle 1990 [1891] ; 36). Logé et nourri, le berger pouvait ainsi être confronté à des usages alimentaires locaux sensiblement différents de sa terre d'origine. C'est qu'il y mangeait comme les autres et le plus souvent possible dans un cadre domestique où des femmes cuisinaient. Seul le fait de consommer un casse-croûte en gardant son troupeau le distinguait alors alimentairement du reste de la communauté locale.

\section{MANGER VÉgÉtARIEN AU PAYS DU CONFIT}

Les produits de l'oie et du canard gras constituant les marqueurs/ différenciateurs par excellence de l'identité alimentaire du sud-ouest de la France, le végétarisme fut d'abord dans cette région une marginalité alimentaire choisie par conviction. Il s'affirma ensuite comme une véritable contre-culture qui ne perdit pas de sa vigueur jusqu'à aujourd'hui, même si les messages de ses représentants les plus convaincus furent brouillés au cours des dernières années par l'émergence d'un "végétarisme tendance ». Avant d'aborder l'histoire du végétarisme, il faut rappeler que ne pas manger des nourritures d'origine animale par conviction ou ne pas le faire pour des raisons économiques ou pratiques, ce n'est pas la même chose. Pour être végétarien, il faut être en mesure de consommer des produits animaux. Il n'y a en effet qu'à cette condition que leur absence de la diète quotidienne ne découle que d'une restriction volontaire du champ des possibles alimentaires. Celui qui aimerait manger de la viande mais se trouve dans l'impossibilité de le faire n'est pas un végétarien ; il est un omnivore contraint de se contenter de nourritures végétales. Une bonne partie de la population du Sud-Ouest se trouva régulièrement dans cette situation jusqu'à ce que ladite région n'entrât dans l'ère d'abondance actuelle où le plus grand nombre peut accéder facilement aux denrées d'origine animale. Songeons au vigoureux octogénaire que Christopher 
Meighan rencontra dans les environs de Luz-Saint-Sauveur vers 1740. Il ne mangeait de la viande qu'une fois par an à l'occasion de la fête patronale. Ce motif revient à dire qu'il le faisait avec plaisir et l'aurait sans doute fait plus fréquemment s'il avait pu se le permettre. Bien qu'il se nourrît tout au long de l'année de pain, de laitages, d'herbes sauvages et de légumes verts, ce montagnard n'était donc en rien un végétarien (1742:10-11). De même, ceux qui renoncent aux viandes à la suite d'une prescription médicale ne deviennent pas nécessairement des végétariens. Lorsque le cardinal de Bernis devint archevêque d'Albi en 1764, cela faisait déjà deux ans qu'il avait écrit à Voltaire: "Je soigne beaucoup mes potagers, qui sont devenus mes nourrices, depuis que je ne mange plus de viande ». Mais ce retournement dans la vie d'un amateur de bonne chère n'avait pas résulté d'une décision personnelle. Ce régime lui avait été conseillé dans le traitement de la goutte et il y resta fidèle par peur de connaître à nouveau les tourments qu'elle provoquait (Bourgoing, 1799 : 93).

Dans le sud-ouest de la France comme ailleurs, l'abstinence perpétuelle adoptée par certaines communautés religieuses régulières peut être considérée comme une forme de végétarisme puisque c'est une décision qui exclut la viande des menus quotidiens. A la fin du XVI siècle, par exemple, il fut précisé dans la règle des feuillantines de MontesquieuVolvestre qu'elles devaient s'abstenir perpétuellement de chair, de vin, de poisson et de sel (Marquet, 1873 : 489). Dans de tels cadres religieux, la mise à l'écart des produits carnés participait de la construction d'un rapport au monde particulier, motivé par une certaine représentation du service de Dieu. En 1284, les moines de l'abbaye de la Sauve-Majeure furent ainsi fortement choqués lorsqu'ils constatèrent qu'un abbé de leur ordre en visite mangeait gras (Berthelet, 1731 : 362). L'abstinence perpétuelle des communautés religieuses est une contrainte imposée au corps pour permettre au spirituel de s'imposer sur le matériel, pas pour le détruire. Logiquement donc, des ordres acceptèrent que l'abstinence perpétuelle pût être suspendue pour des raisons de force majeure. Dans le Toulouse du début du XIII siècle, par exemple, les tout premiers frères prêcheurs ne pouvaient manger de produits carnés que lorsqu'ils étaient atteints d'une maladie grave ${ }^{6}$ (Berthelet, 1731 : 191-192). Cette chair

6 Par la suite, il y eut un certain relâchement dans le suivi des constitutions sur ce point. Au début du XIV siècle, par exemple, il fut décidé que tous les frères prêcheurs vieux, infirmes ou atteints de maladie chronique pourraient, de temps en temps, consommer de la viande avec modération. 
autorisée et parfois imposée aux frères malades souligne que leur alimentation ordinaire caractérisait un choix de vie.

Combien y eût-il de laïcs qui renoncèrent par conviction à la consommation de produits carnés dans le Sud-Ouest avant que JeanAntoine Gleïzès ne le fît, à l'âge de 21 ans, en 1794 ? Nous ne le saurons jamais, mais il est certain que cet homme occupe une place à part dans l'histoire du végétarisme dans le sud-ouest de la France, comme d'ailleurs dans le reste du monde occidental.7 Sa décision d'adopter le " régime des herbes " fut une réaction aux usages de la société dans laquelle il vivait. Une biographie de Gleïzès écrite par un proche montre qu'il exista une relation étroite entre ce choix alimentaire et un dégoût progressif de la chair et du sang. En effet, il abandonna ses études de médecine à cause d'une "répugnance invincible pour les dissections anatomiques». Cette répulsion instinctive pour l'hémoglobine fut indéniablement accentuée par les désillusions que lui provoquèrent les moments les plus sanguinaires d'une révolution française qui l'avait enthousiasmé à ses débuts (Joly, 1856 : 184-185). Cependant, il convient aussi d'expliquer le choix du " régime des herbes " par Jean-Antoine Gleïzès comme il le fit lui-même, c'est-à-dire comme une décision en rupture avec les idées et les actions d'une humanité majoritaire qui se fourvoyait (1840 : v-vi) :

$1^{\circ}$ Que l'homme n'est point animal de proie ; qu'il est, au contraire, par sa nature, la plus douce de toutes les créatures, ainsi que devait l'être la dernière et la plus noble expression d'un Dieu grand, bon et juste.

$2^{\circ}$ Que le meurtre des animaux est la principale source de ses erreurs et de ses crimes, comme l'usage de se nourrir de leurs chairs est la cause prochaine de sa laideur, de ses maladies, et de la courte durée de son existence.

$3^{\circ}$ Que cet état d'égarement est dans une opposition directe avec sa destinée ultérieure qu'il empêche : je veux parler de son immortalité dans le sens communément attaché à ce mot, autrement dit, la vie hors de la terre; tandis que la privation de cet acte, ou, pour parler au positif, le régime des herbes, développe en lui la beauté, l'intelligence, la vertu, et le fruit immortel qui en est le dernier résultat.

Dans son château de La Nogarède (Ariège), Jean-Antoine Gleïzès s'enferma dans une routine alimentaire qu'il ne partagea avec personne, pas même son épouse. Un contemporain écrivit de lui : « pour ménager les

7 Son œuvre alimenta précocement des courants de pensée végétariens en Angleterre, en Allemagne, aux Etats-Unis, etc. (Howard, 1883 : 208-218, Lefèvre, 1904 : 16-20). 
coutumes générales, il mange seul et à part, il ne vit que de lait, de légumes ou de racines apprêtés à l'huile; il ne sert que de sa propre vaisselle et ne peut s'empêcher de témoigner dans toutes occasions l'horreur que lui inspirent les mets que l'on sert sur nos tables» (Nayral, 1835 : 566-567). De fait, Jean-Antoine Gleïzès ne fit pas école autour de sa propriété. Durant un demi-siècle, il ne fut considéré, au mieux, que comme un « excentrique» (Esquiros, $1846: 845$ ). Dans la préface du second volume de Thalysie ou la nowvelle existence, Jean-Antoine Gleïzès ne put d'ailleurs cacher sa déception relative au peu d'intérêt porté à cet ouvrage dans lequel il avait systématisé sa réflexion sur la supériorité du « régime des herbes »: « Je n'ai trouvé partout que répulsion ou, tout au moins, indifférence ». Cependant, il pouvait signaler avec satisfaction une "longue série de séances » que le doyen de la faculté des lettres de Toulouse, Cabantous, avait consacrée au commentaire de son œuvre. Selon lui, elles avaient soulevé un certain enthousiasme chez des membres de l'élite locale (1841: ii-iii)... mais nous ne saurons jamais combien de ces auditeurs renoncèrent au pâté de foie gras.

Par la suite, la sensibilité végétarienne demeura le fait d'une minorité diffuse dans la région. Entre 1899 et 1912, le programme de la Société Végétarienne de France séduisit 24 personnes dans l'ensemble du SudOuest. Mais à regarder dans le détail, seulement 9 d'entre elles devinrent des membres actifs de cette association, c'est-à-dire des adeptes véritables d'une autre façon de manger. Les autres furent des membres associés, c'est-à-dire des individus intéressés par le végétarisme mais qui ne le pratiquaient pas nécessairement. Parmi ces derniers, certains étaient motivés par une curiosité réelle. D’autres semblent avoir été plutôt animés par des intérêts bien sentis. Par exemple, le premier des membres associés habitant dans le Sud-Ouest fut le Bordelais Gasses —un conserveur de légumes soucieux de séduire la clientèle végétarienne comme en témoigne un message publicitaire diffusé dans La réforme alimentaire quelques mois avant son adhésion en juin 1899. Les deux premiers membres actifs de la région furent mentionnés en 1901, l'un était professeur à Albi, l'autre négociant à Tarbes. Les 7 sociétaires inscrits par la suite possédaient comme eux une bonne situation sociale : ils étaient propriétaire, fabricant de bijouterie, ingénieur des mines, pharmacien, abbé, avocat et greffier. La majorité des membres associés évoluaient dans les mêmes sphères sociales que ces adeptes convaincus du végétarisme. Cependant, en 1907, l'entrée dans l'association de C. Loustet, " ouvrier dans l'industrie mécanique du bois » à Toulouse, montre que la sensibilité végétarienne ne fut pas l'apanage exclusif de quelques milieux bourgeois. A la lecture des 24 
adresses, le végétarisme apparaît essentiellement urbain : la Société Végétarienne de France comptait cinq membres à Toulouse, quatre à Bordeaux, trois à Tarbes, deux à Mazamet, un à Albi, un à Dax, un à Lavaur, un à Pau et un à Saint-Jean-de-Luz. L'empreinte de la culture urbaine était par ailleurs perceptible dans le profil des 5 sociétaires qui habitaient à l'écart des villes d'importance. Ils vivaient pour la majorité d'entre eux dans de gros bourgs (Saint-Céré, Ribérac, Cubjac) et se trouvaient souvent là pour des raisons liées à un parcours professionnel, à l'instar du vétérinaire Desplans ou de l'ingénieur Teilhet. ${ }^{8}$ En 1914, nul ne vint fonder dans le Sud-Ouest une communauté anarcho-végétalienne, contrairement à ce qui put être écrit dans des ouvrages récents, par ailleurs excellents, à la faveur d'une erreur toponymique. En effet, le Bascon, où Georges Butaud et Sophie Zaikowska développèrent un végétalisme rigoureux dont la clé de voûte culinaire était une salade composée, n'est pas un village gascon mais un hameau des environs de Château-Thierry (Butaud, 1930 : 62). Tout au long du xx siècle, le végétarisme resta dans la région une affaire de mangeurs ou de familles de mangeurs relativement isolées. Le plus souvent, il fut une contre-culture alimentaire latente, parfois mise en avant afin d'essayer de convaincre de son bien-fondé des consommateurs de viande. Au début des années 2000, par exemple, après plus d'un demi-siècle de pratique végétarienne, les époux Cléro de Dolmayrac (Lot-et-Garonne) se souvenaient qu'ils s'étaient " pas mal démenés » pour promouvoir autour d'eux cette façon de manger en essayant, toujours, d'éviter le prosélytisme virulent.

Peu à peu le militantisme végétarien s'organisa dans la région. A partir de l'extrême fin du XXe siècle, les initiatives de promotion locales de modes de nutrition alternatifs se multiplièrent avec des moyens et des effets qui demeurèrent souvent très limités. Au début des années 2000, par exemple, l'Association Végétarienne et Végétalienne d'Informations installait régulièrement un stand rudimentaire sur le marché dominical de la place Saint-Sernin de Toulouse. ${ }^{9}$ Si certains des tracts présentaient des adresses de restaurants végétariens ou de commerces alternatifs toulousains, l'essentiel du propos que l'association diffusait était beaucoup plus général. Ce faisant, elle invitait plus à prendre le contre-pied d'un modèle de consommation global qu'à se déterminer face à des traits particuliers de la

8 Etude réalisée à partir de La réforme alimentaire. Organe des Sociétés Végétariennes de France et de Belgique, 1899-1913.

9 Cette association fut créée en 1997. 
culture alimentaire locale. Le passant pouvait y trouver immanquablement un tract Boucherie? Non merci, mais je n'y jamais vu un dépliant Cassoulet! Saveurs de la mort ou quelque chose de semblable. Ici, le végétarien militant ou le sympathisant cessait d'être un individu à la conduite alimentaire marginale dans une ville carnassière pour devenir un membre d'une communauté de mangeurs universelle dotée d'une éthique et d'une cuisine qui lui étaient propres. L'association jouait aussi la carte de la pédagogie culinaire en offrant une brochure de 36 pages : 278 recettes de cuisine végétalienne.

Dès cette époque, un militantisme végétalien commença à s'exprimer sous des formes inédites dans le Sud-Ouest : visibles, bruyantes... " extrémistes " comme certains pouvaient le dire alors. Certaines actions n'étaient pas sans rappeler les alliances anarcho-végétariennes qui avaient existé dans d'autres régions par le passé. Un quotidien anarchiste local soutint fortement, par exemple, l'organisation par l'Association Contre la Consommation d'Etres Sensibles d'une marche végétarienne nue, le 14 juillet 2003, à Toulouse. Dans de telles circonstances, l'affirmation d'une pratique végétarienne ou d'un mode de vie vegan s'intégrait dans une contestation globale de la société et participait d'une culture en opposition, qui se souhaitait en rupture totale avec celle de la majorité. ${ }^{10}$ Aujourd'hui, le militantisme vegan/antispéciste reste toujours fort actif et créatif. Le 31 octobre 2017, par exemple, L 214 organisa un défilé d' «employés d'abattoir » à Bordeaux et à Toulouse pour sensibiliser le public à sa doctrine anti-viande dans l'ambiance festive de la nuit d'Halloween. ${ }^{11}$

Un militantisme aussi visible n'intéressa jamais plus qu'une minorité de végétaliens. La majorité des végétariens se contenta de manger à sa façon dans une société au sein de laquelle son choix n'était pas toujours compris. Devenue correspondante dans le Gers de l'Association Végétarienne de France, Christine Comté Théry se souvient sur sa page internet de son existence de végétarienne avant de connaître cette structure : «J'avais cette impression d'être 'hors norme'. Le végétarisme dans le Gers [...] tu n'as rien trouvé d'autre m'ont dit quelques proches $»{ }^{12}$ Une autre situation classiquement rencontrée fut une difficulté d'assimilation des spécificités

10 «14 juillet à Toulouse: première marche végétarienne nue », L'en dehors, 07/01/2003.

11 L. Larbani, "Bordeaux: pour Halloween, les militants vegans de L214 organisent un défilé macabre ", Sud-Ouest, 31/10/2017. L214 est une association antispéciste créée en 2008.

12 https://www.vegetarisme.fr/c\&d/c.comte_thery/. 
de la diète végétarienne par des personnes pourtant de bonne volonté. Arrivée à Bordeaux pour y poursuivre des études supérieures à la fin des années 1990, G. réussit sans trop de difficultés à s'alimenter en végétarienne dans cette métropole régionale. Néanmoins, les « essaie de goûter » ou le " mais le canard, ce n'est pas de la viande » ne lui furent pas épargnés, tandis que ses beaux-parents ne s'habituèrent que difficilement à l'idée qu'elle ne supportât pas les lardons dans les petits pois. En cela, le SudOuest ne se démarqua pas vraiment des autres régions qu'elle avait connues avant de s'y installer. ${ }^{13}$ Ici comme ailleurs, la racine de bien des malentendus se trouva dans les représentations alimentaires des non-végétariens. En 2004, par exemple, les bénévoles en charge du stand restauration d'un festival organisé dans un village du Pays Basque intérieur considéraient que leur sandwich «thon crudités » était végétarien! Point de mauvaise foi de leur part, pour eux, le poisson n'était pas viande et pas vraiment chair.

De fait, l'offre végétarienne en restauration demeura longtemps extrêmement réduite dans le Sud-Ouest. Au cours des deux dernières décennies, elle s'est considérablement diversifiée portée par une croissance de la demande que le destin de La Faim des Haricots suffit à rappeler. En 1996, l'ouverture de cet établissement purement végétarien à Blagnac paraissait un pari très risqué. Son propriétaire ouvrit une succursale à Labège en 2001, puis une autre à Toulouse en 2005. En 2017, l'établissement de Blagnac changea d'adresse pour se doter d'une capacité de service en intérieur de 86 couverts ! ${ }^{14}$ Dans les restaurants traditionnels et les supermarchés, l'offre en plats et en produits « végétariens » augmenta aussi considérablement. Parallèlement, des restaurants scolaires commencèrent à offrir quotidiennement des menus végétariens pour répondre aux préoccupations de certains parents. Tel est le cas à Pessac depuis la rentrée 2016. Dans cette ville comme dans beaucoup d'autres, cette proposition alimentaire n'est pas exactement une réponse apportée aux besoins de la minorité d'élèves végétariens, qui fut longtemps la grande oubliée des administrateurs de cantines. Préparé avec des produits « d'origine végétale ou animale comme le poisson, les œufs, le lait ou le miel », ce menu peut d'ailleurs ne pas être conforme aux exigences des végétaliens mais aussi des ovo-lacto-végétariens stricts. En revanche, il permet de montrer ostensiblement que la municipalité est préoccupée par les enjeux environnementaux et par la santé publique. A l'heure de débats houleux

13 Entretien, Bordeaux, 05/2005.

14 «La Faim des Haricots a déménagé », La Dépêche du Midi, 14/10/2017. 


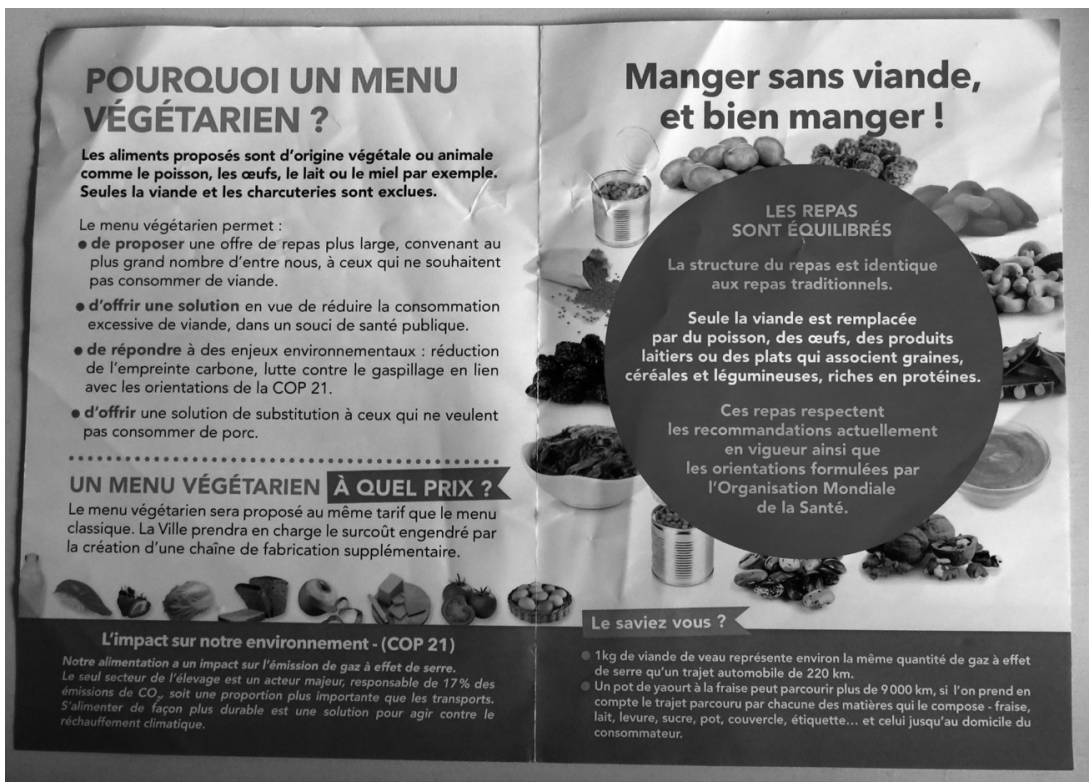

Figure 3 : Présentation du menu végétarien proposé dans les écoles, Pessac (Gironde), 2017.

sur la laïcité et sur la place de l'Islam en France, il offre aussi « une solution de substitution à ceux qui ne veulent pas consommer de porc » [Figure 3]! Aujourd'hui, donc, une certaine idée du végétarisme peut être bien utile en politique, tandis que certaines conceptions du végétarisme sont éminemment politiques.

\section{Manger dans la pauvreté, ENTRE DÉBROUILLE ET ASSISTANCE}

La pauvreté est plurielle. Le seuil de la privation de moyens qui la caractérise varie selon les époques ou les sociétés. En outre, il existe invariablement plusieurs façons d'être pauvre, par la durée de l'état d'infériorité, par le degré d'indigence atteint (Goglin, 1976 : 15-16), etc. Tant qu'ils disposent d'un domicile, d'un foyer et d'un minimum d'ustensiles, les pauvres parviennent tant bien que mal à maintenir une conduite alimentaire classique, quand bien même la faiblesse de leurs ressources limite considérablement la gamme d'aliments qui leur est accessible. 
Au milieu des années 2000, par exemple, les ménages qui bénéficiaient de l'aide alimentaire en denrées fraîches de la délégation bayonnaise de la Croix Rouge disposaient encore d'un domicile où cuisiner et manger. Mais tel ne fut jamais le cas de tous les pauvres. Aujourd'hui comme hier, celui qui devient clochard perd en même temps que son logement la possibilité de préparer de véritables repas chauds et se trouve contraint d'adopter une nouvelle conduite alimentaire qui, entre débrouille et assistance, déstructure peu à peu son bagage culturel originel (Moreau de Bellaing, $1998: 136-137){ }^{15}$

Les vagabonds constituèrent longtemps des personnages familiers des campagnes du sud-ouest de la France. Poussés loin de chez eux par la faim ou par un autre motif, ils parcouraient les routes en vivant d'aumônes; que certains d'entre eux complétaient par le produit de quelques maraudes. En octobre 1763, par exemple, deux soldats invalides croisèrent un troupeau d'oies sur la route qui les conduisait de Dax à Bayonne. L'un d'eux tua un des palmipèdes avec son bâton et l'enveloppa dans son mouchoir. Pour la faire cuire, ils s'arrangèrent avec une dénommée Bertrane qui partagea leur repas. Elle les rejoignit en prison, lorsqu'arrêtés après une tentative manquée de « vol d'oiseaux morts » sur le marché de Bayonne, ils avouèrent leur premier délit. ${ }^{16} \mathrm{~A}$ cette époque, de tels exemples de basculement dans une délinquance plus ou moins grave ne manquaient pas. Associés à de vieilles angoisses, ils alimentaient une méfiance voire une hostilité vis-à-vis des errants (Duby et Wallon, 1992 [1975] : 284-285). Cependant, en dépit des soupçons et des craintes, une forme d'assistance aux mendiants itinérants se maintint durablement dans les campagnes du Sud-Ouest. Dans les années 1780, par exemple, l'usage était « établi » chez les paysans du causse de recevoir les mendiants qui se présentaient à la porte de leur maison en leur donnant deux repas et un morceau de pain quand ils repartaient (Richeprey, 1952 : 192). Né en 1928, J. L. de Hères (HautesPyrénées) garda le souvenir que, dans son enfance, lorsqu'un vagabond venait à passer à proximité de la demeure familiale, sa grand-mère lui offrait l'hospitalité. Un repas composé de deux œufs, d'une tranche de jambon, d'un quignon de pain frotté à l'ail et de quelques rasades de vin

15 « Je les appelle «clochards » parce qu'il faut bien leur donner un nom. Celui-là n'est en rien meilleur que les autres, sinon qu'il renvoie à des images partagées, en France, par tout le monde. Mais s'il en est besoin d'autres, SDF, sans abri, routards ou grands exclus feront tout aussi bien l'affaire». (Declerck, 2003 [2001] : 12).

16 Arch. mun. Bayonne, FF 250, 08/10/1763. 
rouge lui était servi et, lorsqu'il reprenait la route, elle prenait soin de lui remettre une bonne ration de pain, au moins suffisante pour s'alimenter durant une journée. ${ }^{17}$

Dans les années 1900, les mendiants des petites Landes demandaient de la nourriture en disant : "La charitat, Daune, per amour dou boun Diou!" ["La charité, madame, pour l'amour du bon Dieu »] (Laporte-Castède, 2004 [1981] : 176). Cette phrase rappelle que l'assistance accordée par les paysans aux plus pauvres qu'eux trouvait ses racines dans l'idée que le bon chrétien devait donner l'aumône aux pauvres, qui étaient des images incarnées du Christ souffrant et des intercesseurs privilégiés auprès de Dieu (Gutton, 1974 : 93-157). Bien qu'elle eût été fortement remise en cause dès le début des temps modernes, cette représentation du pauvre était restée bien établie dans les mentalités rurales. Des contes collectés au Pays Basque dans la seconde moitié du XIX ${ }^{e}$ siècle en sont des transpositions limpides. Dans l'un d'eux, la Vierge vient éprouver en personne une paysanne occupée à cuire son pain et la châtie finalement de sa pingrerie. ${ }^{18}$ En invitant à suivre un idéal de partage, cette histoire moralisante rappelle que le vagabond rencontrait sur sa route des portes ouvertes, entrouvertes ou fermées. Que celles-ci fussent rares ou nombreuses sur son chemin, le mendiant des campagnes, même le plus débrouillard, ne pouvait faire autre chose que manger où il se trouvait, avec ce qu'il y recevait ou ce qu'il y prenait. Il changeait de pain comme il changeait d'abri pour la nuit, au gré de la générosité d'autrui ou de ses propres audaces. De fait, son déracinement et son errance étaient aussi alimentaires.

Même composée en grande partie par des aumônes ou des dons plus ou moins déguisés, l'alimentation du pauvre sédentaire des campagnes donne à l'inverse l'impression d'une plus grande stabilité et d'une plus grande normalité. Il mangeait dans un village et, en restant dans une gamme de denrées minimales, comme ceux de ce village. Tant que l'économie de subsistances locale reposa très largement sur l'autoconsommation, l'écart entre ses possibilités alimentaires et celles du plus grand nombre put même paraître limité. Avec la pleine intégration des campagnes à l'économie de marché et à la société de consommation, l'écart se fit beaucoup plus criant et la détresse alimentaire, longtemps plus masquée qu'inexistante, s'affirma.

17 Entretien, Séméac, 06/2003.

18 "Les pains de la Sainte Vierge ", parabole recueillie en Soule auprès d'une informatrice âgée de soixante-quatorze ans (Cerquand, $1875: 16$ ). 
Au milieu des années 2000, par exemple, les Restos du Cœur intervenaient dans de nombreuses localités rurales : Brantôme en Périgord, Ayherre en Basse-Navarre, etc.

Dans un milieu resserré comme la société urbaine, les contrastes furent accentués et les tensions augmentées. La pauvreté s'y montra précocement plus préoccupante et l'assistance plus urgente selon un point de vue au moins autant politique que caritatif. En 1534, les Capitouls édictèrent une ordonnance sur la nourriture des pauvres. Ce texte établissait une distinction nette entre les «pauvres valides étrangers » qui devaient être expulsés, les mendiants originaires de Toulouse qui devaient être employés à des travaux d'utilité générale et nourris en retour et les pauvres honteux, veuves et mères de petits enfants qui devaient recevoir une assistance à leur domicile. Il prévoyait également une réorganisation du système de distribution des aumônes en créant notamment des bailles en charge de celle-ci. ${ }^{19}$ Tout au long de l'Epoque Moderne, cette idée de refouler les vagabonds pour concentrer l'assistance sur les pauvres domiciliés fut régulièrement répétée, mais sans jamais vraiment parvenir à la mettre en application de façon efficace. En 1629, par exemple, de «pauvres familles étrangères, n'ayant aucune vacation pour gagner leur vie, mais seulement mendiant leur pain » bénéficièrent de l'aide (distributions de fèves et de soupes grasses, etc.) que les consuls d'Agen avaient décidé d'apporter aux pauvres de leur ville dans une situation particulièrement difficile. Plusieurs décennies plus tard, la jurade d'Agen tenta à plusieurs reprises mais toujours sans succès de "purger la ville de ses vagabonds » afin de concentrer la charité locale sur les pauvres de sa juridiction (Baumont, $1999: 156,205)$.

Dès le XVI ${ }^{e}$ siècle, les mendiants urbains commencèrent à déranger et à inquiéter. Peu à peu, leur non travail devint le résultat d'un vice et les actes délictueux auxquels se livraient certains d'entre eux, la preuve d'une dangerosité de classe. Sur ce terreau de craintes naquit un désir d'enfermement des pauvres, dont les effets sur la réalité urbaine restèrent somme toute limités (Foucault, 1976 [1961] : 56-91). Les pauvres qui franchissaient le seuil des hôpitaux généraux, sous la contrainte ou poussés par un dénuement extrême, y étaient nourris en échange de leur travail ou en raison de leur invalidité. En plein XVIII siècle, l'ordinaire des pensionnaires de Saint-Joseph de la Grave se composait pour l'essentiel

19 Arch. mun. Toulouse, AA 17/65, 1534. 
d'un pain de qualité variable et de soupe. Le rôle que le riz y tenait aux côtés des classiques légumes secs révèle un régime de pauvres. Cependant, la présence assez régulière d'un peu de viande fraîche, de poisson séché ou de fromage dans les rations montre qu'il s'agissait d'un régime amélioré en regard de ce que beaucoup des enfermés auraient pu espérer manger hors les murs de cette institution toulousaine (Taillefer, 2000 : 113-114). En l'an IV, l'alimentation servie dans le réfectoire de l'hôpital des incurables de Bordeaux était d'une nature fort semblable. Le riz et les pommes de terre typiques des menus de pauvres figuraient auprès du pain, des pois et des fèves. Toutefois, l'apparition dans les menus d'un peu de viande (bøuf, veau ou mouton) et de poisson salé les rendait plus satisfaisants que ce qui pouvait s'obtenir au quotidien en mendiant (Allemandou et Le Pennec, 1995 : 269).

Beaucoup de pauvres restèrent néanmoins en dehors des structures d'enfermement ou parvinrent à s'en échapper. Outre sur la mendicité et la débrouille, ils pouvaient compter pour survivre sur des formes d'actions caritatives héritées du passé. A la fin du XVIII siècle, par exemple, les curés de certaines paroisses bordelaises faisaient bénéficier leurs pauvres honteux mais aussi certains " oiseaux de passage » de distributions de pain, de viande ou même de monnaie (Butel et Poussou, 1980 : 158-159). Pour sa part, une confrérie agenaise organisait un "bouillon des pauvres » (Baumont, 1999 : 205). Après la Révolution, une assistance alimentaire de même nature continua d'être apportée aux pauvres urbains par diverses structures religieuses ou laïques, alors que la stratégie d'enfermement se faisait plus sournoise et que la volonté de refoulement des vagabonds demeurait toujours aussi forte. Qu'ils fussent aidés par le bureau municipal de bienfaisance de Bayonne, la société protestante de bienfaisance des Dames (Bordeaux, 1829) ou toute autre institution équivalente, les pauvres assistés des villes restaient fondamentalement des mangeurs de pain et de soupe (Pontet, 1991 : 224 ; Diebolt, $1990: 31$ ).

$\mathrm{Au} \mathrm{XVII}$ siècle, la grande ivrognerie n'était pas inconnue dans l'univers des gueux, comme le rappellent notamment des habitudes contractées par certains anciens soldats avant leur entrée à l'institution royale des Invalides (Buttet, 1984 : 47-49). Cependant, la régularité de cette pratique impliquait un accès facile au vin, que ne possédaient pas tous les misérables. La baisse du prix du vin et d'autres boissons dans la seconde moitié du XIX siècle changea la donne (Nourrisson, 1990 : 27-38). La consommation d'alcool put donc prendre une place bien plus considérable qu'auparavant dans la vie de nombreux clochards, dissolvant les gains de la mendicité, certes, 
mais aussi l'horreur de la misère. A l'instar des gueilloux qui hantaient le quartier bordelais de Mériadeck dans les années 1950, beaucoup devinrent des buveurs excessifs, pas mal des alcooliques chroniques (Fournier, 1999: 185-186).

Les progrès enregistrés par la démocratie sociale dans la seconde moitié du $\mathrm{XX}^{\mathrm{e}}$ siècle furent considérables. Ils se traduisirent notamment par le développement de nouvelles formes d'actions sociales alimentaires. Entre 1949 et 1978, par exemple, 36 foyers municipaux dispensant des repas aux personnes âgées furent mis en place à Bordeaux (Sauras, 1978 : 33). Il y eut aussi la création de divers minima sociaux. En 1997, par exemple, ils permettaient de mieux vivre au quotidien à près de $5 \%$ de la population de l'agglomération de Montauban. Trois ans plus tard, à $12 \%$ de celle de Castres. ${ }^{20}$

Au début du XXI ${ }^{\text {e }}$ siècle, cependant, la pauvreté et l'errance urbaine demeuraient des réalités dans le Sud-Ouest. En juillet 2005, par exemple, les bocaux de nourriture, les bouteilles et le cubitainer de gros vin rangés par un sans-abri bayonnais sur une poutre du pont Henri Grenet montraient l'importance des lieux dans les possibilités alimentaires des Sans Domicile Fixe. Un robuste pont de pierre n'aurait pas offert les mêmes possibilités d'appropriation de l'espace que la structure métallique aérienne qui avait permis la création de ce garde-manger ombragé. Pour partie d'entre eux récupérés, ces objets rappelaient également l'importance de la « débrouille » sous toutes ses formes dans la conduite alimentaire des sans-abri. Dans le Bordeaux du début des années 1990, les vagabonds stationnés aux abords du marché des Capucins pouvaient notamment échanger le déchargement d'un camion contre un repas (Bernard et Dupouey-Bordenave, $1993: 123$ ).

Evoluant dans un milieu urbain où la consommation était reine, des Sans Domicile Fixe arrivaient à se nourrir en partie avec ce que les autres citadins gaspillaient. En 2004, un Bordelais à la rue depuis vingt-six ans visitait régulièrement le container dans lequel le personnel d'un magasin La Brioche Dorée jetait les invendus. Un jour d'avril, il composa son repas de midi à partir de ce qu'il y trouva. Délaissant les sandwichs au fromage, il choisit de consommer un "sandwich avec du jambon de Bayonne », un autre fait avec « du pâté avec du cornichon », un troisième

20 Ces minima furent RMI/RSA, API, AAH, AS et ASS. Chiffres INSEE, 2000 et 2003. 
«jambon d'York avec de l'harissa » puis deux pains aux raisins (Collombat, 2003-2004 : 16). Certains obtenaient par la mendicité l'argent nécessaire à l'achat d'aliments bon marché ou de boissons alcoolisées. Logiquement, ces dernières devenaient prioritaires s'ils étaient alcoolo-dépendants (Gaboriau, 1993 : 178-187). Quand un passant offrait de la nourriture, celle-ci était diversement appréciée. Après huit ans de rue, par exemple, M. BA en avait marre de recevoir des chocolatines, car il n'aimait pas le sucré. Il évoquait avec à peine un peu plus de bonheur les sandwiches qui finissaient certains jours par s'accumuler dans son sac à dos (Collombat, 2003-2004 : 38-39).

Diverses institutions caritatives apportaient chacune à leur manière une aide alimentaire à la population fort hétérogène des sans abri. Refusés par certains, les repas dispensés par ces organismes jouaient un rôle très important dans la structuration de la vie alimentaire de beaucoup d'autres. Bordelaise depuis peu, une femme âgée de trente-cinq ans ne faisait pas d'autre véritable repas dans la journée que celui qui lui était offert le soir à la Halte de Nuit; elle y prenait aussi son café du matin. Dans ce lieu où la majorité des cinquante personnes qu'il pouvait accueillir chaque soir venaient pour "se remplir ", elle appréciait la possibilité de dîner avec un petit groupe de connaissances et de redonner une dimension conviviale à l'acte alimentaire. Il faut dire que l'alimentation ne comptait pas parmi ses premières préoccupations, celles-ci étant l'obtention d'un logement et d'un travail (Collombat, 2003-2004 : 5-8). Certes, cette femme s'exprimait après trois semaines sans logis. Mais les pratiques et les discours de Sans Domicile Fixe de longue date montraient également que l'ingestion de nourritures était vécue et pensée comme une nécessité, mais sûrement pas comme une priorité. M. BE, après six ou sept ans de rue à Bordeaux, reconnaissait qu'il buvait facilement mais se présentait comme un artiste de la faim, capable de "rester plusieurs jours sans manger sans problème » (Collombat, 2003-2004 : 11-12). Cet homme, qui, dans sa vie d'avant, avait aimé cuisiner, décrivit à son interlocutrice la préparation d'un bouf bourguignon... à la façon de son père. Comme lui, bien des Sans Domicile Fixe pouvaient conserver une mémoire, une nostalgie de leur vie alimentaire d'avant la rue. En d'autres termes, leur conduite quotidienne ne parvient pas nécessairement à effacer leur identité alimentaire originelle; même lorsqu'elle la met fréquemment à mal. Après plusieurs années d'une vie dans la rue, un SDF d'origine algérienne reconnaissait qu'il avait mangé du porc " quand sinon [c'était] suicide ». Mais il se souvenait pour partie en arabe de la chorba associée à son pays natal (Collombat, 2003-2004 : 12). 
Le SDF mangeait où il se trouvait, quel que fût son bagage mental, ses préférences ou ses dégoûts. L'étranger s'alimentait sur les marges d'un paysage alimentaire qui lui était étranger, le naufragé de l'existence sur celles du paysage alimentaire qu'il connaissait depuis l'enfance. Un samedi matin de janvier 2005, par exemple, deux clochards profitèrent largement du tourrin brûlant et des tartines de rillettes offerts aux visiteurs du marché au gras fermier de Périgueux. Tous les regards alentour furent loin de se faire approbateurs, mais les deux hommes parvinrent à manger tranquillement. L'un d'eux, l'homme tatoué, m'expliqua plus tard que de tels marchés faisaient partie des bons plans de "débrouille » dans cette ville. ${ }^{21} \mathrm{~A}$ Bayonne, quelques semaines plus tôt, le confit de canard avait figuré au menu d'un réveillon de Noël organisé par un collectif d'associations avec le soutien de la mairie. Ici, les gens de la rue avait donc été invités à partager un monument local, eux qui devaient généralement choisir leurs nourritures ordinaires dans les secteurs du paysage alimentaire où l'investissement symbolique était particulièrement faible. Il est vrai que la fête est la rupture avec le quotidien ${ }^{22} \ldots$

Chaude, réconfortante, nutritive et facile à préparer à partir des légumes les plus divers, la soupe ne manque pas d'atouts pour qui souhaite aider alimentairement son prochain au quotidien. Au début des années 1730, par exemple, les religieuses de l'hôpital de Bayonne la préparaient pour les pauvres, en respectant autant que possible la formule suivante : «deux poignées de choux ou équivalent en fèves, naves, citrouilles ou autres choses selon la saison; quatre poignées d'oignons ou de poireaux, deux poignées de persil, une poignée d'herbes fines $»{ }^{23}$ Dans la même ville, au milieu des années 2000, le Cacao Club, une association célèbre pour la soupe à l'ail qu'elle servit longtemps pendant les fêtes locales, pouvait certains après-midi d'hiver préparer une soupe plus conventionnelle pour qu'elle fût le soir venu servie à des SDF [Figure 4]. Aujourd'hui, la soupe reste essentielle. Entre le 14 novembre 2016 et le 31 mars 2017, par exemple, elle n’a jamais manqué au menu des démunis bayonnais qui fréquentaient la Table du Soir.

Symbole de la charité alimentaire, la distribution de soupe aux gens de la rue peut être mise en scène à des fins politiques. Le soir de Noël 2016,

21 Entretien, Périgueux, 21/01/2005.

22 B. Lassalle, "Chaleureuse solidarité au menu des gens de la rue ", Sud-Onest, 26/12/2004.

23 Arch. dép. Pyrénées-Atlantiques, E 73, 14/06/1732. 


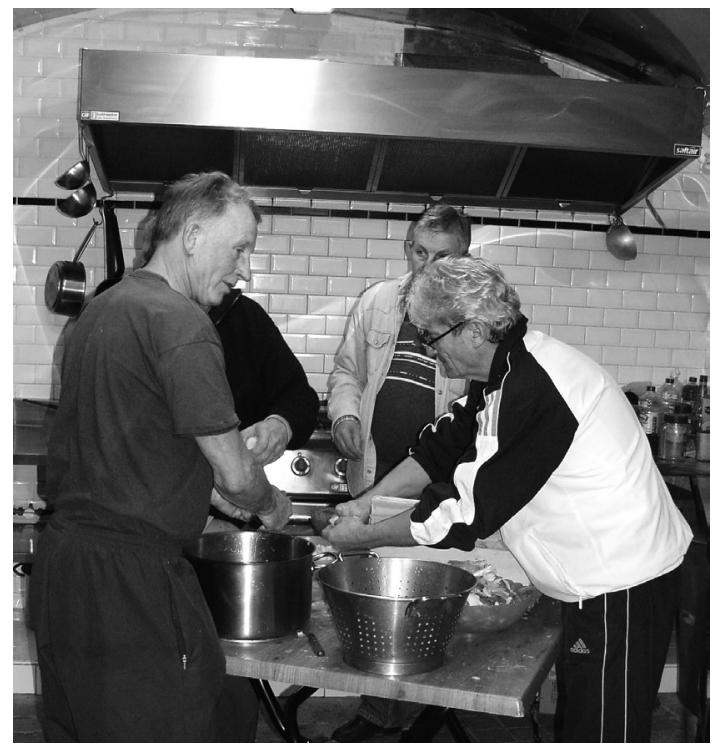

Figure 4 : Préparation d'une soupe caritative au Cacao Club, Bayonne (Pyrénées-Atlantiques), 2006.

deux militants du Front National distribuèrent de la «soupe au cochon » à des SDF dans les rues d'Angoulême. ${ }^{24}$ Nouveau dans la région, ce type d'opérations est pratiqué par des groupes d'extrême droite français depuis 2004. Le seul ingrédient important dans cette soupe est évident le porc, ce qui explique que des variantes non liquides de ce plat discriminatoire sont possibles. Un jour de janvier 2018, par exemple, six militants du Cercle Souveraineté et Identité Toulousaine offrirent à des SDF des sandwichs aux rillettes de $\operatorname{porc}^{25} \ldots$ Ces distributions ne sont pas charitables, car elles ne sont pas désintéressées. Leur finalité est claire : créer un microévénement médiatisé qui puisse servir de tribune éphémère pour lancer aux oreilles des Français des slogans pensés pour provoquer un sursaut identitaire nationaliste, mais dont l'effet sur le plus grand nombre semble

24 J. Prigent, "Angoulême : une soupe aux relents d'extrême droite pour Noël », Charente libre, 27/12/2016.

25 «Dans les rues de Toulouse, ils distribuent des sandwichs au porc à des 'SDF français' », La Dépêche du Midi, 25/01/2018. 
être tout au contraire le déclenchement d'un réflexe humaniste universaliste. Le 14 janvier 2017, un collectif d'associations d'Angoulême répondit à la «soupe au cochon" par une «soupe pour tous aux légumes bio »!26 Quelle que soit l'idéologie qui motive leur distribution, ces soupes ne constituent pour les SDF que des options de " plan débrouille » supplémentaires, plus ou moins appréciées, plus ou moins évitables... comme peuvent l'être des créations vraiment charitables comme le restaurant social ouvert par la Société de Saint-Vincent-Paul à Bordeaux, etc.

\section{Conclusion}

Notre parcours en compagnie des bergers, des végétariens et des clochards s'achève. Leurs exemples nous montrèrent comment des facteurs particuliers, ici une activité professionnelle ou une décision idéologique, pouvaient façonner des sous-cultures alimentaires propres à des groupes au sein d'une société. Les manières de cuisiner et de manger ou les relations avec les aliments qui caractérisent chacune d'elles peuvent diverger plus ou moins fortement, par contrainte ou par choix, du modèle alimentaire partagé par le plus grand nombre. Lorsqu'elles prennent volontairement le contre-pied des façons de se nourrir et de penser l'alimentation majoritaires, elles deviennent des contre-cultures alimentaires. Jean-Antoine Gleïzès et les personnes de la rue nous invitèrent aussi à considérer la marginalité alimentaire dans sa diversité. Lorsqu'un jeune homme s'oblige en toute solitude à manger selon des normes en rupture avec la culture de ses contemporains, il choisit une conduite ; lorsqu'un SDF doit se débrouiller pour manger sans pouvoir nécessairement tenir compte des catégories établies par sa propre culture alimentaire, il est contraint à une conduite. L'un mange ce qu'il veut, l'autre pour l'essentiel ce qu'il peut. Bien sûr, cela peut être fort différent. Mais tous deux ont des conduites alimentaires qui sont marginales en regard de celles du plus grand nombre.

Bien d'autres mangeurs, solitaires ou membres de groupes dotés d'une sous-culture remarquable, auraient pu également nous accompagner. Comme les bergers, les végétariens et les clochards, ils auraient mangé différemment dans le sud-ouest de la France. Comme eux, ils nous auraient ainsi rappelé la complexité des identités vécues au quotidien par les habitants

26 C. Lasaires, "Angoulême : une soupe pour tous en réponse de celle au cochon ", Charente libre, 16/01/2017. 
d'un territoire. En effet, l'identité d'un sujet est déterminée par une multitude de données élémentaires, les unes comptant plus que les autres à un instant donné. En certaines circonstances, le fait de vivre ici pourra compter plus que celui d'être né ici ou là, d'être de telle appartenance religieuse, d'exercer telle profession, d'être un homme ou une femme, d'être de droite ou de gauche, de préférer l'Aviron Bayonnais à l'Union Sportive Montalbanaise, etc. En d'autres moments, l'ordre d'importance pourra être totalement différent. Il y a des situations dans lesquelles les habitants du Sud-Ouest peuvent accorder une extrême importance aux monuments du paysage alimentaire du lieu où ils vivent : quartier, ville, département, région administrative, espace culturel, etc. En d'autres moments, ils mobiliseront les valeurs symboliques d'aliments bien différents ou élaboreront de subtiles combinaisons. De plus, vivre son identité alimentaire au quotidien entraîne parfois des négociations, implique de composer avec des restrictions d'offre, de temps, de moyens, etc.

Pour tout cela, il est sans doute plus judicieux de prendre en compte la complexité des réalités locales que de leur opposer des «idéaux » d'identité. En mars 2018, par exemple, Toulouse demeurait incontestablement une étape gourmande riche en monuments gourmands pour qui visitait le SudOuest : cassoulet, gâteau du Fénétra, violettes confites, etc. Cependant, elle était aussi une ville où l'on trouvait 13 établissements McDonald's, plus de 80 marchands de kebabs, des boucheries halal, des charcuteries aveyronnaises, des supermarchés asiatiques, des épiceries africaines ou vegan, un marchand de bent macrobiotique, etc. En bref, des joyaux gastronomiques faisaient l'identité alimentaire de Toulouse, mais les identités alimentaires des Toulousains et les manières qu'ils avaient de les vivre au quotidien étaient multiples.

\section{RÉFÉRENCES}

AfFre, Henri, 1974 [1903], Dictionnaire des institutions, mours et coutumes du Ronergue. Marseille, Laffitte Reprints. 468 p.

Allemandou, Bernard et Jean-Jacques Le PenneC, 1995, 60000 pauvres à Bordeaux! La politique d'aide sociale sous la révolution. Talence, MSHA. 306 p.

Barandiarán, José Miguel de, 1987, « Notas sueltas para un estudio de la vida popular en Heleta », Anuario de Eusko-Folklore, 34: 65-78.

Barandiarán, José Miguel de, 1955, « Notas sobre la vida pastoril de Ibarre », Anuario de Eusko-Folklore, 15: 39-46.

Baumont, Stéphane, dir., 1999, Histoire d'Agen. Toulouse, Privat. 320 p. 
Bernard, Marie-Christine et Jeanne Dupouey-Bordenave, 1993, « Les bénéficiaires ne forment pas une tribu ». Dans J.-P Augustin et J. Pailhe, éds., Vers une géographie de la pauvreté. Le RMI en Gironde. Talence, Cesurb : 119-125.

BERTHELET, Grégoire, 1731, Traité historique et moral de l'abstinence de la Viande. Rouen, Veuve Hérault. 521 p.

Blot, Jacques, 1984, Artzainak. Saint-Sébastien et Bayonne, Elkar. 195 p.

Bourgoing, Jean François de, 1799, Correspondance de Voltaire et du cardinal de Bernis depuis 1761 jusqu'à 1777. Paris, Dupont. 276 p.

Butaud, Georges, 1930, Le végétalisme. Edmont, Publications du Végétalien. 70 p. et $48 \mathrm{p}$.

Butel, Paul et Poussou, Jean-Pierre, 1980, La vie quotidienne à Bordeaux au xviiie siècle. Paris, Hachette. 344 p.

ButTet, Henri de, 1984, "Le vin des invalides au temps de Louis XIV », Les boissons: production et consommation aux xixe et xxe siècles. Paris, Ed CTHS : 39-51.

Capdevielle, François, 1990 [1891], La vallée d'Ossau. Bayonne, Libro-liber. 249 p.

CAZAurAng, Jean-Jacques, 1983, Scènes de la vie rurale en Béarn. Le Coteau, Horvath. 263 p.

Cerquand, Jean-François, 1875, Légendes et récits populaires du pays basque. Pau, Ribaut. 74 p.

Collombat, Julie, 2003-2004, L'alimentation des personnes Sans Domicile Fixe. Mémoire professionnel, ISPED, Université de Bordeaux II. 61 p. et 56 p.

DARDENnE, Pierre, 1990 [1805], Essai sur la statistique du département de l'Ariège. Saint-Girons, Le Boulbi. 406 p.

Declerck, Patrick, 2003 [2001], Les naufragés. Avec les clochards de Paris. Paris, Plon. 457 p.

Diebolt, Evelyne, 1990, La maison de santé protestante de Bordeaux (1863-1934). Toulouse, Erès. 187 p.

De Silva, Cara, 1996, In Memory's Kitchen. A Legacy from the Women of Terezin. Jason Aronson, Northvale. 110 p.

Duby, Georges et Armand Wallon, dirs., 1992 [1975], Histoire de la France rurale. De 1340 à 1789 . Paris, Seuil. 658 p.

DUHART, Frédéric, 2009, De confits en foies gras. Une histoire des oies et des canards du Sud-Onest. Bayonne et Saint-Sébastien, Elkar. 518 p.

Duvert, Michel et Arnaud Aguergaray, 1993, "Investissement de l'espace: données ethnographiques recueillies dans le Goiberri (Hauteurs) navarrais et souletin ", Anuario de Eusko-Folklore, 38 : 135-154.

DuverT, Michel, Bernard DeCHA et Claude LABAT, 1998, Jean Baratçabal raconte la vie dans un village basque de Soule au début du xxe siècle. Bayonne, Lauburu. 443 p. 
Esquiros, Alphonse, 1846, «Les excentriques de la littérature et de la science », $L a$ revue des deux mondes, 15 : 837-857.

ETCHEBARNe, Erramun, 1989, Erramun Harginaren oroitzapenak. Saint-Sébastien, Etor. 153 p.

ETNIKER, 1990, Atlas etnográfico de Vasconia: La alimentación domestica en Vasconia. Bilbao, Eusko Jaurlaritza et Etniker Euskalerria. 755 p.

ETNIKER, 2000, Atlas etnográfico de Vasconia: Ganadería y pastoreo en Vasconia. Bilbao, Eusko Jaurlaritza et Etniker Euskalerria. 1020 p.

Faustin, Régis, 2004, Estives. Oloron-Sainte-Marie, Monhelios. 120 p.

Froidour, Louis de, 1892 [1675-1685], Mémoire du pays et des états de Bigorre. Paris et Tarbes, Honoré Champion et Baylac. 390 p.

FOURNIER, Jean-François, 1999, "La vie quotidienne des habitants du quartier Mériadeck à Bordeaux dans les années 1950-1960 ", Revue archéologique de Bordeaux, $90: 181-190$.

Foucault, Michel, 1976 [1961], Histoire de la folie à l'âge classique. Paris, Gallimard. 583 p.

Garric, Yves, 2001, Paroles de burons. Rodez, Fil d'Ariane Editeur. 250 p.

Girou De BuZAReingues, Charles, 1833, Mémoires statistiques sur les montagnes d'Aubrac et sur la manipulation du lait dans ces montagnes. Paris, Huzard. 28 p.

Gleizes, Jean-Antoine, 1840-1841, Thalysie ou la nouvelle existence. Paris, L. Desessart. 2 tomes, 617 p. et 361 p.

Goglin, Jean-Louis, 1976, Les misérables dans l'Occident médiéval. Paris, Seuil. $242 \mathrm{p}$.

Greenspoon, Leonard J., Ronald A. Simkins et Gerald SHAPiro, éds., 2005, Food and Judaism. Omaha, Creighton University Press. 343 p.

GutTon, Jean-Pierre, 1974, Les pauvres en Europe à l'Epoque Moderne. Paris, PUF. 208 p.

HOward, Williams, 1883, The Ethics of Diet: A Catena of Authorities Deprecatory of the Practice of Flesh-eating. London, Pitman. 394 p.

Joly, Nicolas, 1856, «J.-A. Gleizes et le régime des herbes », Revue de l'Académie de Toulouse, $3: 183-204$.

Lamazou, Etienne, 1988, L'ours et les brebis. Mémoires d'un berger transhumant des Pyrénées à la Gironde. Paris, Seghers. 204 p.

Laporte-Castede, Georgette, 2004 [1981], Pain de seigle et vin de grives. Bordeaux, Aubéron. 284 p.

Lefebvre, Thierry, «La transhumance dans les Basses-Pyrénées », Annales de géographie, 37, $1928: 35-60$.

Le Roy Ladurie, Emmanuel, 1982 [1975], Montaillou, village occitan de 1294 à 1324. Paris, Gallimard. 642 p. 
LeFEVRe, Jules, 1904, Examen scientifique du végétarisme. Paris, Société végétarienne de France. 163 p.

Levi-Strauss, Claude, 1987 [1952], Race et histoire. Paris, Seuil. 127 p.

MARQueT, Henri, 1873, "Les premières feuillantines », Revue de Gascogne. Bulletin mensuel de la Société historique de Gascogne, 14 : 485-495.

MARres, Paul, 1935, Les grands causses. Etude de géographie physique et humaine. Tours, Arrault. 2 tomes, 213 p. et 446 p.

Meighan, Christopher, 1742, A Treatise of the Nature and Powers of Bareges's Baths and Waters. London, Meighan. 146 p.

Merlin, Annie et Alain-Yves Beaujour, 1978, Les mangeurs du Rouergue. Paris, Duculot. 205 p.

Moreau de Bellaing, Louis, 1998, "L'alimentation chez les Sans Domicile Fixe ", Journal des anthropologues, 74 : 135-141.

NaYral, Magloire, 1835, Biographie castraise. Castres, Vidal. Tome 3, 611 p.

Nourrisson, Didier, 1990, Le buveur au xixe siècle. Paris, Albin Michel. 378 p.

Отт, sandra, 1993 [1981], Le cercle des montagnes. Une communauté pastorale basque. Paris, CTHS. 268 p.

Peillen, Jean et Dominique Peillen, 1965, "L'élevage ovin dans le Pays de Soule », Bulletin du Musée Basque, 28 : 49-60.

PonTET, Josette, dir., 1991, Histoire de Bayonne. Toulouse, Privat. 336 p.

RiCHEPREY, J. F. Henry de, 1952-1967 [1780-1785], Journal des voyages en Haute Guienne. Rodez, CAHR. 483 p. et 559 p.

Riviere, Georges-Henri, dir., 1970-1986, L'Aubrac. Etude ethnologique, linguistique, agronomique et économique d'un établissement bumain. Paris, CNRS. 8 tomes.

Soulet, Jean-François, 1974, La vie quotidienne dans les Pyrénées sous l'Ancien Régime du xvie au xviiie siècle. Paris, Hachette. 319 p.

TAillefer, François, 1939, "Le Vicdessos », Revue géographique des Pyrénées et du Sud-Onest, $10: 161-268$.

Taillefer, Michel, 2000, Vivre à Toulouse sous l'Ancien Régime. Paris, Perrin. $424 \mathrm{p}$.

ToAfF, Ariel, 2000, Mangiare alla gindia. Bologne, Il Mulino. 222 p. 
